\title{
Exploring Realistic Mathematics Education in a Flipped Classroom Context at the Tertiary Level
}

\author{
Helge Fredriksen ${ }^{1,2}$ (1)
}

Received: 11 February 2019 / Accepted: 8 January 2020 / Published online: 1 February 2020

(C) The Author(s) 2020

\begin{abstract}
Flipped classroom (FC) pedagogical frameworks have recently gained considerable popularity, especially at secondary school levels. However, there are rich opportunities to explore FC at tertiary levels, but progress on the area requires instructors' attention to well-designed tasks for students' collaborative learning. Realistic Mathematics Education (RME) provides a foundation for the development of such tasks. This article advances research on the role of task design in a FC context by considering how RME heuristics may be developed to include the out-of-class phase, where students prepare for in-class work with videos. This adaption, named flipped RME classroom design, is explored through two realizations of such a design with a group of computer engineering students during their first year of studying compulsory mathematics. Thematic analysis of the classroom observations shows that students' modelling activity in-class is supported by the design of an out-of-class component in combination with teacher guidance of students' modelling activity.
\end{abstract}

Keywords Flipped classroom modelling - Realistic mathematics education · Undergraduate mathematics

\section{Introduction}

While traditional lecture-based teaching has been a norm in tertiary mathematics education, there has emerged an understanding that it is necessary to introduce collaborative, inquiry-oriented learning pedagogies like flipped classroom (FC) also at this level (Love, Hodge, Grandgenett, \& Swift, 2014). Such approaches can be effective on performance scales like fail rates and students' success in subsequent courses (Rasmussen \& Wawro, 2017). One of the key benefits with these approaches, as

Helge Fredriksen

helge.fredriksen@uia.no

1 Department of Mathematical Sciences, University of Agder, Kristiansand, Norway

2 Department of Computer Science and Computational Engineering, UiT - The Arctic University of Norway, Narvik, Norway 
opposed to traditional lectures, is the focus on students' engagement, participation and conceptual understanding. As such, the teacher may facilitate students' collective efforts to become participants in the mathematical problem-solving community (Kuiper, Carver, Posner, \& Everson, 2015).

Current literature reviews on the FC learning framework indicates a great variety of implementations (Bishop \& Verleger, 2013; Lundin, Bergviken Rensfeldt, Hillman, Lantz-Andersson, \& Peterson, 2018; O'Flaherty \& Phillips, 2015). Even though it is difficult to give an accurate definition of FC pedagogy, Bishop and Verleger (2013) provide us with these principles: (1) direct computer-based individual instruction outside the classroom through video lectures and (2) interactive group learning activities inside the classroom. One of the key ideas is that students should be 'primed' with the initial knowledge about the mathematics that they will further explore when attending teacher-facilitated in-class activities, hopefully at a more conceptual level. As such, the significance of the FC framework is the possibility for enhanced quality of in-class learning. As FC approaches prompts the facilitator to put emphasis on these activities, there is a need to develop frameworks that offer heuristics for meaningful task design, also taking the out-of-class component into consideration. Indeed, special care needs to be taken towards such task designs to ensure alignment of in-class and out-of-class preparations (Strayer, 2012). The research presented in this article takes the novel approach of considering RME as a theoretical basis for the development of such resources in a $\mathrm{FC}$ context.

This is a study of how RME can be integrated as a theoretical background for the activities in a FC. Firstly, I present the theory of RME and how it fits with the FC approach in the following section. This section is concluded by stating the research goal of the paper, in addition to presenting an extension to the RME theory which I call pre-situational activity. Then, the methodology section presents the flipped RME classroom designs which were enacted to form the empirical basis of the paper, in addition to providing an introduction to how thematic analysis was used to analyse the data. The results of the analysis is presented in the section 'Thematic analysis of the activity', where the six themes are presented with illustrative excerpts from the observations. The section 'Discussion' relates the findings of the thematic analysis to the theory, and the paper concludes by considering potential future refinements of RME integration in FC instructional designs.

\section{Theoretical Background}

RME was originally proposed by Freudenthal (1983) to position students as inventors and researchers when working with mathematical ideas. Freudenthal was deeply against the traditional mathematics education at the time, which he considered to be presented as fragments of abstract ideas not connected to the real world (Gravemeijer \& Doorman, 1999, p. 116). To counter this, he suggested an educational view of mathematics as a human activity and not as a ready-made-system (Freudenthal, 1973). In this respect, the reality aspect of mathematical tasks does not necessarily refer to applications found in the real world, but can also be 'mathematical real' in the sense that they build upon previous mathematical knowledge (Rasmussen \& Blumenfeld, 2007). The idea is to create a foundation for substantial participation in established 
mathematical practices rather than focusing on constructing bridges between students' current level of understanding and established canonical ideas in mathematics.

RME is particularly associated with instructional design, in which the mathematical tasks students engage with should guide learners from informal to formal mathematical knowledge. Cobb, Zhao, and Visnovska (2008) mention three central tenets of the design theory in RME. The first tenet is that an instructional sequence or a task design should be experimentally real for the students, so that they can engage immediately in personally meaningful mathematical activity. During this phase, students use mathematics as a tool to organize problems in a realistic context, a process called horizontal mathematization (Van Den Heuvel-Panhuizen, 2003).

The second central tenet is that the informal ways of speaking, symbolizing and reasoning established during the initial phase of the task should form the basis for the progressive process of vertical mathematization. 'Vertical mathematization refers to mathematizing one's own mathematical activity. Through vertical mathematization, the student reaches a higher level of mathematics. It is in the process of progressive mathematization - which comprises both the horizontal and vertical component - that the students construct (new) mathematics.' (Gravemeijer \& Doorman, 1999, p. 117).

The third tenet is about supporting the process of vertical mathematization. One of the primary means of support involves activities in which students create and elaborate symbolic models of their informal mathematical activity. A central part of this process is the teacher guidance, where students' 'model-of' a contextualized situation becomes a 'model-for' more general mathematical reasoning (Gravemeijer \& Doorman, 1999). This process is often referred to as students' guided reinvention of mathematics.

Gravemeijer (1997) mentions four levels of abstraction which the transition from model-of to model-for passes through. The first level concerns acting in the real situation of the task, where domain-specific, situational knowledge is utilized. At the referential level, which is considered the second level, the model of the situation is developed. At this level, students combine aspects from the situational stage with mental organizing activity to form an initial systemic view of the situation. When the students are familiar with this model-of and its various aspects, the attention shifts towards a model-for, resulting in a new mathematical reality for the student. As Rasmussen and Blumenfeld (2007, p. 196) mention, this shift is compatible with what Sfard (1991) calls the process of reification. This third level is called the general level which involves being able to see the model in a de-contextualized role, in which the student no longer needs to think of the problem situation to give meaning to it. Finally, one may consider a fourth, formal level, where students reason with the model at a purely formal mathematical level.

Most studies of RME originates at a K-12 level, in which the reinvention of mathematics is rooted in concrete realities where the use of mediating tools, graphs and diagrams are important at the situational level. Only later do analytical expressions enter the modelling activity. However, employing RME at the tertiary level might require a certain basic knowledge about abstract mathematics like vectors and trigonometry. Indeed, Rasmussen and Blumenfeld (2007) argue that analytical expressions can serve as a tool for reasoning at all phases of the model-of/model-for transition. The claim is based on empirical evidence from undergraduate students' work on enacted RME instructional design in the field of differential equations. This is consistent with the principle of building on students' prior ideas and experiences, which 
Kieran, Doorman and Ohtani (2015, p. 53) highlight as important for RME task design. In a FC setting, this prior knowledge base could partly be formed by the preparatory engagement with out-of-class videos.

RME aligns well with many principles found in various definitions of FC. For example, Hamdan McKnight, McKnight, and Arfstrom (2013) mention the shift in 'learning culture' as one of the pillars of flipped learning. This shift consists of moving away from a teacher-centred model, where the 'teacher is the main source of information' or the 'sage on the stage', towards a collaborative learning arena, 'where in-class time is meant for exploring topics in greater depth and creating richer learning opportunities'. However, this setting may lead students into a vacuum if the tasks that students encounter in class do not appear as a meaningful extension of the out-of-class component (Strayer, 2012). As such, they need to be provided ample opportunity to engage with the topic at hand. RME designed learning resources could form this desired platform due to its heavy reliance on students' own participation.

Van den Heuvel-Panhuizen and Drijvers (2014) list a set of seven principles that RME designers should adhere to, among them the interactivity principle. This principle highlights the idea that learning mathematics is not purely an individual pursuit, but rather a collaborative activity, where group work and whole-class discussions should form an important part of the enactment of the task.

To understand what I mean with collaborative activity, we may contrast it with the term cooperation. While cooperation can be defined as students splitting a task into subtasks and working individually on these, collaboration is considered to be the joint effort in the group to solve the problem collectively (Hadjerrouit, 2012, p. 47). How this plays out in the classroom is to a large extent given by the task(s) at hand. While certain tasks will stimulate more collaborative, mutual engagement towards solving the task, others may direct students towards individual work. Although collaborative activity is not a prerequisite for FC as such, it seems hardly necessary to arrange in-class sessions if interactions with peers and the teacher do not take place. Indeed, collaboration among students is considered an important in-class component in most studies on FC (Abeysekera \& Dawson, 2015; Blair, Maharaj, \& Primus, 2015; Hwang, Lai, \& Wang, 2015).

Moving from a teacher-centred to a collaborative teaching style does not reduce the significance of the teacher. The teacher becomes an important facilitator for the transition between the model-of to model-for, even more crucial than the conveyer of mathematical ideas when lecturing. She/he 'has the obligation of enculturating students into the discourse and conventional representation forms of the broader community while honouring and building on students' contributions' (Rasmussen \& Marrongelle, 2006, p. 395), and this applies in an FC where teachers are considered to represent the expert that provides the means for collaborative learning (Bergmann \& Sams, 2012). However, there seems to be little research that focuses specifically on the mathematics teachers' role in the FC framework.

Also, I was not able to find previous studies that focused on utilizing RME as an overall framework for learning and teaching in an FC context. Some studies have looked at how the in-class time could be spent on modelling activities to enhance students' critical thinking skills, but not from an RME perspective. Stillman (2017) reviewed how modelling of real-world problems was being utilized in FC contexts at tertiary mathematics education. She found that few studies reported on empirical evidence in this field. 
Considering the lack of studies in this area, and the desire to advance research on the role of task design for FC frameworks, my research question is formulated as follows:

In which ways can flipped classroom with an RME task design facilitate students' collaborative efforts towards guided reinvention?

To operationalize this research question, I studied the enacted outcome of two flipped RME classroom designs.

\section{The Flipped RME Classroom Design}

As Kieran et al. (2015) indicate, RME is an evolving theory. To integrate the FC framework with RME task design, it is necessary to extend the RME heuristics to link in-class and out-of-class student activity. To allow the outof-class video preparation to integrate with the four stages of Gravemeijer (1997) (situational, referential, general, formal), I introduce a pre-situational stage. During the pre-situational video-watching and note-taking stage, students should engage critically with the mathematical definitions, concepts, results and examples introduced by the teacher at this stage. This forms a basis for the horizontal mathematization during the situational and referential stages in-class. As such, the designer needs to pay attention to how the videos could form consistent support for students' work in class. Figure 1 illustrates the model, where the two spheres of out-of-class preparation and in-class collaboration are depicted. Students' activities out-of-class consists of watching a certain set of designated videos on a computer screen or other media devices. The role of this pre-situational activity is to prepare students for in-class collaboration, hence the arrow between the boxes. In class, the students divide in a number of groups (illustrated by group $\mathrm{i}$ and $\mathrm{j}$ in the figure) and are provided with task(s) adhering to RME heuristics with the various activity levels. Task content should draw on definitions and concepts presented in the videos. The work with collaboration in groups and plenary presentations are supported by the teacher.

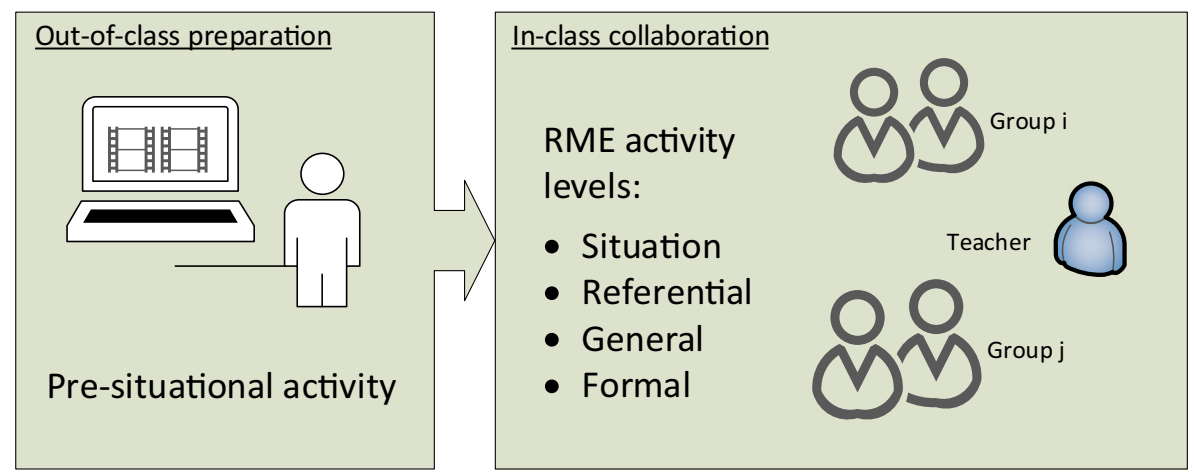

Fig. 1 Flipped RME classroom design 


\section{Methodology}

This section first presents the context of the study and the conduct of the classroom sessions. I then describe the two flipped RME classroom designs, which are the basis for my observations. The section closes with a description of how I conducted thematic analysis on the data.

\section{The Context of the Study}

The two enacted flipped RME classroom designs reported on are part of a larger study where a cohort of 15 computer engineering students was subjected to FC teaching in their mathematics sessions throughout their first year of study at a Norwegian University. The students had two mathematics sessions each week; their out-of-class preparation for these sessions was to watch 2-5 videos, each about 10 min in length. Students usually had 2 days to prepare using these videos. The learning management system utilized for this experiment allowed me to see how much time each student had been spending on the individual video prior to the in-class session. Each in-class session lasted for $1.5 \mathrm{~h}$.

\section{Design and Data Collection}

The out-of-class component of the flipped RME classroom design consisted of two different types of instructional videos for each session, introductory and illustrative. The introductory video provided the students with an overview of the content, such as providing basic definitions and operations and connecting current content with prior mathematical topics. The illustrative videos were designed to follow up the introductory videos with example problems to show procedural techniques. The problems solved in these videos were a mix of ordinary textbook-type problems and contextualized problems, such as modelling of populations and how to set up transformation matrices for specific cases of scaling and rotation. The major role of the videos were thus to prime students with definitions, concepts and solution techniques that could be utilized in class. The idea was to provide students with an analytical baseline that could be considered 'real' for students to employ at the situational stage of the RME task in class. The tasks given were conceptual in nature, requiring students to do more than simply applying the procedures presented in the videos.

I filmed two separate groups of students throughout two classroom sessions using separate high-definition cameras. These groups of students were picked randomly to ensure that I would get a good cross-section of the student mass. I did not want to handpick students that were good or bad at particular areas, since this would form a bias in my research data. The choice to record the work in all four different student groups, which were different groups all together, was done partly to enhance measurement validity (Bryman, 2008), and partly due to a richer data material for the analysis.

Classroom interactions fell into two different categories: whole-class discussions with either a student or me in front of the class or students working in small groups. The whole-class discussions took the form of a mini-lecture by me or by a selected student working through the ideas of the group on the whiteboard. As a routine, I repeated the main points in the videos through a mini-lecture at the beginning of the lesson. These 
mini-lectures were usually interactive in the sense that I would question the students about the topic while lecturing, or students would interrupt me to ask questions. Sometimes there were break-out sessions, when there was struggle across several groups on a common topic that called for whole-class clarification and discussion. At the end of the sessions, the students had to share their solutions with the other groups, followed by an attempt by me to draw on these contributions to synthesize a common understanding of work with the task(s). In addition, some time was spent fostering ideas on generalized mathematical concepts behind the modelling activity.

The tasks students considered in class for this study were based on previous research. One of these, the skewed $\mathrm{N}$ task described in Andrews-Larson, Wawro, and Zandieh (2017), was developed based on RME design principles and was appropriate to exemplify matrix multiplication for the purpose of linear transformations. The double Ferris wheel task, which was the basis for the second task design, is described in Sweeney and Rasmussen (2014). This task did not mention RME principles explicitly, but the task sequence already contained the progression from informal to formal levels that characterize RME, so little redesign of the in-class component was found necessary. The previous research on these tasks reportedly spurred a discursive atmosphere during group work, which I found appealing considering the research goal for this study which emphasizes students' collaboration.

\section{The Double Ferris Wheel}

The beginning of the students' autumn term started with a module of four FC sessions revisiting trigonometry and vectors from upper secondary school. The last session in this module was based on a flipped RME classroom design, where the first video in the out-of-class session (https://www.youtube.com/watch?v=dQOT63TJQJI\&) showed an animation on how the sine function could be traced out by traversing the unit circle and plotting the y-value (see Fig. 2).

The next two videos (https://www.youtube.com/watch?v=xNkBXAnRCPs and https://www.youtube.com/watch? $\mathrm{v}=\mathrm{hPW} 8 \mathrm{tmN} 1 \mathrm{Hu} 4)$ showed how one could model a real-life example on wolf populations; how to sketch a trigonometric function based on given phase shift, amplitude, period and equilibrium line and conversely how to

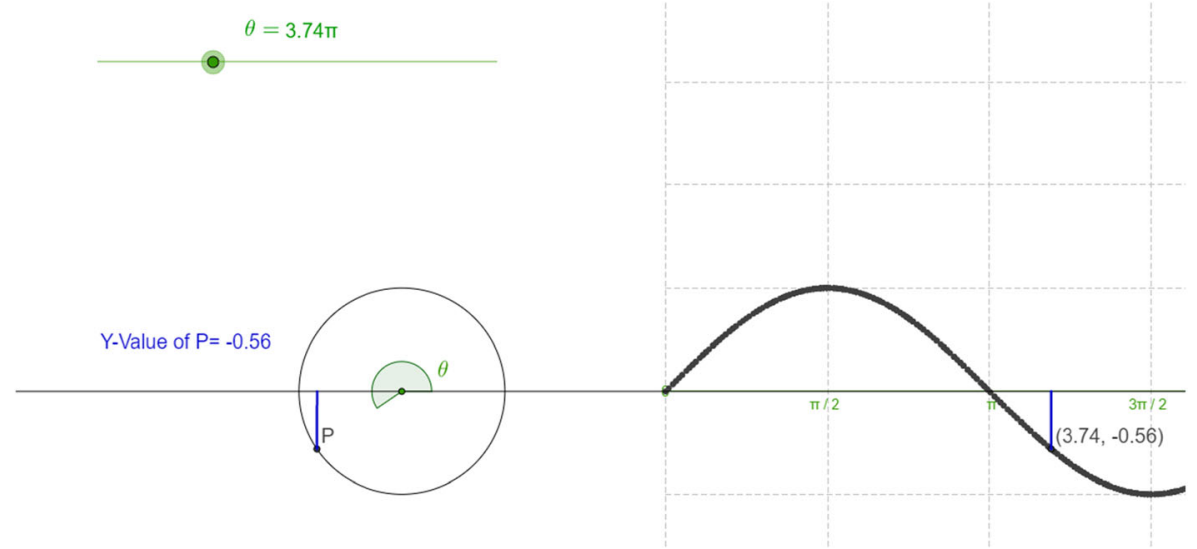

Fig. 2 Tracing the unit circle y-component to the sine function in the instruction video 
determine the values of the parameters from a graphical representation. These videos were produced by a fellow researcher Matt Voigt.

The task for the in-class session was based on describing the motion of a double Ferris wheel driver. The students were given a simulation in GeoGebra which they could watch on their computer while they worked with the task. The interested reader can open it at this link (http://sigmaa.maa.org/rume/crume2017/Applet.html).

The double Ferris wheel consisted of two separate wheels rotating with the same speed and centred at each end of a larger rotating bar having a different angular velocity than the wheels. The position of the rider was clearly marked on the circumference on one of the wheels, and the height above ground level could be read from the applet at all times (see Fig. 3). The final task given to the students was to make a mathematical model of the dynamics of this height.

I filmed two groups of students working on this task. For later reference, group 1 was Sam, Joe, Freddy and Bert, and group 2 was Eve, Bill, Matt and Perry. The assigned names are pseudonyms.

\section{The Skewed N}

The second flipped RME classroom design took place during the spring term, where the topic was basic linear algebra. The session was held after the students had just learned about matrix multiplication and the method of Gauss elimination. One of many uses of matrices in computer science is the ease of describing certain two-dimensional transformations like rotation and scaling. This gave me the opportunity to provide students with experimentally real tasks. I drew on a sequence of tasks, developed by the Inquiry-Oriented Linear Algebra project (http://iola.math.vt.edu/) and, in particular, the 'Italicizing N' task.

Prior to working with this in-class, the students had watched two different videos on how matrix multiplication could be used for extending the concept of functions by introducing the idea of linear transformation. The initial video (https://www.youtube.

Height: 30.81

ఐStop Large Bar

चStop Small Wheel

Reset to Start Position

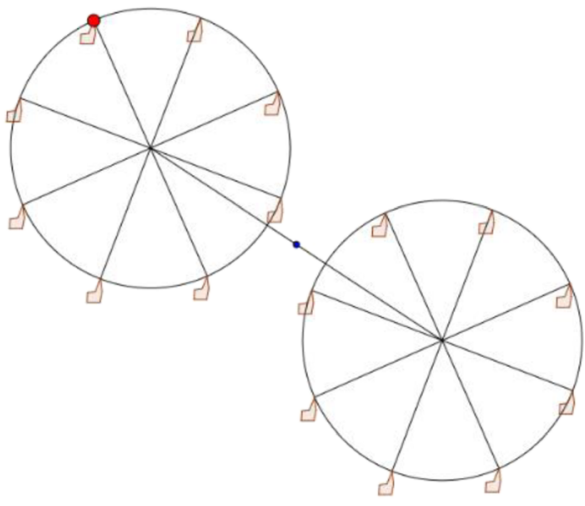

Fig. 3 The double Ferris wheel simulation 
$\mathrm{com} /$ watch? $\mathrm{v}=$ GemhjcmJi-l) showed the general idea of transforming vectors from a $m$ dimensional domain $\mathbb{R}^{m}$ to the $n$-dimesional co-domain $\mathbb{R}^{n}$ defined through $T: \boldsymbol{y}=\mathrm{A} \boldsymbol{x}$, where $\mathrm{A}$ is the $n \mathrm{x} m$ transformation matrix, $\boldsymbol{x}$ a vector in the domain and $\boldsymbol{y}$ the transformed vector in the co-domain. The other video (https://www.youtube.com/watch?v=NiO5Bg5 ouYY) considered the application of linear transformations in two-dimensional vector graphics, showing how to define a $2 \times 2$ transformation matrix for scaling and rotation, including examples. The videos for this session were made by the author. Figure 4 shows the initial task the students were given for the in-class group work.

The two teams that were filmed working on this was group 1 consisting of Bill, Freddy, Joe and Mick, while group 2 consisted of Sam, Alvin and Bert. Again, assigned names are pseudonyms.

\section{Data Analysis}

The four group work sessions were all transcribed verbatim, also highlighting gestures that students would use to emphasize their statements. I analysed student work using thematic analysis, which is a method for identifying, analysing and reporting patterns (themes) within data (Braun \& Clarke, 2006). Thematic analysis has similarities to grounded theory (Corbin $\&$ Strauss, 2008), but a difference is that thematic analysis accepts the adoption of a theoretical pre-defined framework for the coding. This is convenient in cases where one needs to approach the data with such a framework in mind, which in my case is RME theory.

Thematic analysis includes the phases of researcher familiarization, generating codes, searching for themes, reviewing themes, defining and naming themes and writing a report (Braun \& Clarke, 2006). Familiarization with the data was supported by initially writing a descriptive account of each classroom session (Miles \& Huberman, 1994), where the sessions were separated into chunks of activity with timestamps attached and a neutral description of the event.

Coding was done by marking passages of text that seem to highlight a specific idea or activity that gave meaning to me as a researcher. Thus, the coding was based on my interpretation on what happened in these passages, but due to the theory-driven nature

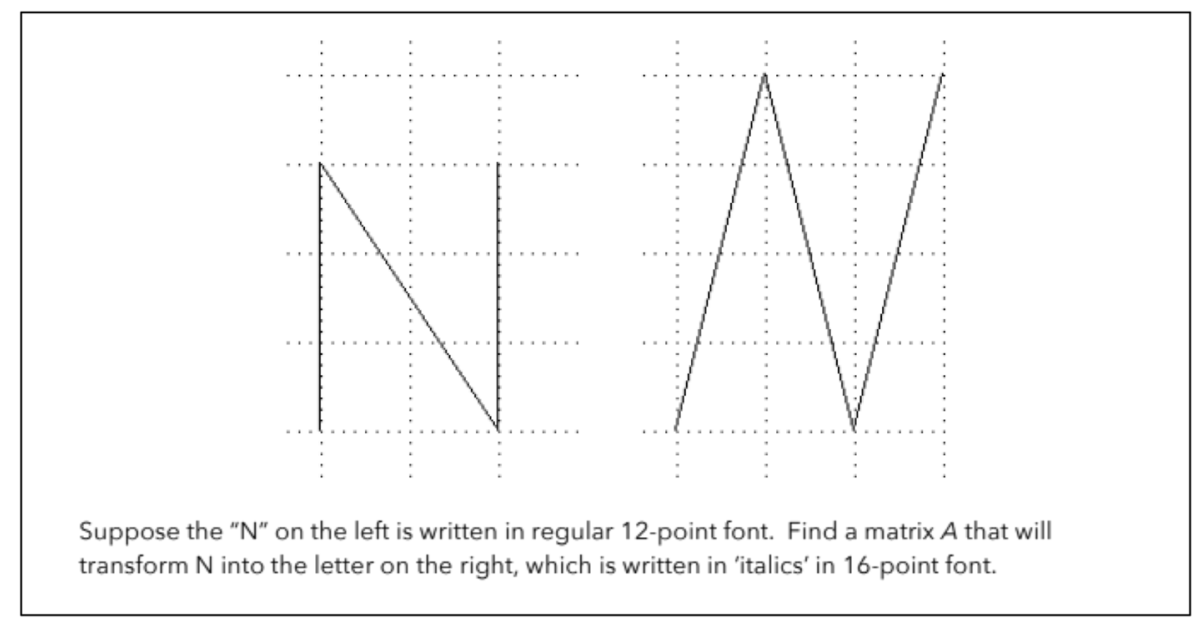

Fig. 4 The italicizing $\mathrm{N}$ problem 
of the coding, this interpretation was coloured by the overarching theory of RME. The analysis was a movement back and forth between these codes and the actual data in search for meaningful patterns to emerge, creating new codes as the process evolved. As such, the transcripts were re-read several times where some passages would be recoded, and others would be left out. The re-coding process was also meaningful in the sense that it brought forward ideas on emergent themes.

As an example of the process of coding the data material, I consider an excerpt when group 1 was working on the Ferris wheel modelling, right after a period of situational activity where they all had made individual sketches of how they thought the graph would look like. Prior to the excerpt below, Bert had realized that the graph was synthesized by two individual ones and Freddy voiced some initial informal ideas about the phase shift.

239: Sam: If the ground is the $\mathrm{x}$-axis, then the baseline will be ... (points to the computer screen where the simulation is showing).

240: Bert: Mhm ...

241: Freddy: I suggest that we make two functions that is zero when ... They are not zero, but $3 \pi / 2$ (points to $3 \pi / 2$ on a handout that depicts exact values of sine and cosine on the unit circle) on $2 \pi$.

Here, the visual connection between the Ferris wheel circle and the unit circle seemed to be guiding Freddy towards an understanding of phase shift. The connection between the sine and the unit circle was the focus of attention in one of the out-of-class videos that was part of this FC session, justifying the code RECALL. Another code attached to this excerpt was 'context-related informal modelling', abbreviated to CRIM. This code was used to depict moments where students were using established mathematical terms from the sine model like 'baseline', 'phase shift', 'amplitude' and similar, but in an informal manner, not tied to concrete quantities. A similar code attached to other fragments of text was 'context-related model adaption', abbreviated to CRMA, which was used to describe the ways students attempted to connect the situational quantities in the task to the formal mathematical model under consideration.

The various codes were then collected into themes. For instance, the codes CRIM and CRMA were gathered in the theme 'referential activity', where the model-of activity of students was a pertinent way to synthesize the idea behind these codes. Attaching these to the referential stage, as the theme name indicates, can be justified since they describe moments when students attempt to connect situational quantities with pre-situational mathematical models from the videos.

Some excerpts were linked with several codes and thus provided evidence of interrelated themes. For example, the above mentioned code RECALL was associated with 'presituational referencing'. Since the same excerpt also was attached with the code CRIM linked to referential activity, this indicates that the excerpt can relate to both themes.

The initial themes were then reviewed and visualized in thematic maps, akin to mind-maps. This was performed on a per-session basis, so that in all, four such thematic maps were produced. By analysing the data another time with the initial themes in mind, the themes were refined into fewer themes and synthesized into a global thematic map transcending the data corpus. This can be exemplified by the 
initial themes 'investigating movement in applet', 'graph sketching' and 'gesturing to reproduce movement' aggregating to the final theme 'situational activity'. During this revisiting of themes, some of the themes initially created were found to relate only to a specific situation which one student group encountered, not to overarching themes, and were discarded. Some of the codes belonging to these themes were then retrospectively assigned to other final themes.

The product of this process was the creation of a report, highlighting specific excerpts from the transcripts to support each theme. This report forms the basis of my results from this research.

\section{Thematic Analysis of the Activity}

Through the thematic analysis, I identified six major themes in my thematic analysis which relates to different stages of the group work. Although the two sessions were different in nature, they shared the same background design of RME. As such, it is natural that I found the final themes to reflect the stages of RME modelling activity. However, I also found additional themes related to the guidance of the teacher and the role of the out-of-class phase in FC:

- Pre-situational referencing

- Situational activity

- Guidance on model-of

- Referential activity

- Guidance on model-for

- General activity and vertical mathematization

I consider each theme to capture a unique type of activity found in the classroom discussions between the students and between me as a teacher and the students. During this analysis, I present extracts from the transcripts to illustrate the ideas behind the themes, in addition to providing analytical narratives to link the extracts to the theoretical constructs. The extracts have been translated from Norwegian to English.

\section{Pre-Situational Referencing}

Recall that the pre-situational stage was introduced as a way to include students' out-ofclass work with the videos to prepare for in-class activities in an FC setting.

The students' starting point with the skewed $\mathrm{N}$ task was how vectors or points describing the original letter to be transformed might fit into the matrix multiplication, and how this was related to the unknown matrix they were supposed to find. This excerpt is collected from the start of the transcript of group 2. A reference to the videos can be observed in Alvin's contribution:

4: Alvin: I think the transformation matrix must be reflecting that you scale it with a certain amount and then you rotate, it was like that in the videos, that you could use the transformation matrix to rotate vectors.

5: Sam: Yes, that could be the case. 
6: Alvin: That you use both scaling and rotation.

It can be observed that not only does Alvin associate the pictured transformation with the examples in the videos, he is also able to use the words 'scaling' and 'rotation' fluently, words that have a special mathematical meaning in this situation.

\section{Situational Activity}

Initially, the students engaged in various discussions to make sense of the task. Such activity is often referred to as situational activity in RME theory and is described as acting in a particular task setting that is experimentally real for the students (Rasmussen \& Blumenfeld, 2007). These discussions were characterized by students utilizing sketches, gestures, calculators and visual media like the simulation and figures given in the task to aid in their initial representation of the task. In the Ferris wheel task, this representation was graphical, either through sketching height versus time or drawing an intuitive picture of the movement, as exemplified in Figure 5.

An example from this period of students' meaning-making can be seen in group 1, where Joe, Simon and Bert are watching and elaborating on what they see in the applet:

2: Joe: I guess it's ['it' referring to the simulation] just to show that it [presumably 'it' refers to the height of the rider] will go up and down in the graph for sure.

3: Simon: It's not the time in seconds, it's really just to depict that when one has gone one round, the other has proceeded four rounds.

4: Bert: But where is that said?

5: Simon: It is not said, but one can just count when you look at this illustration here.

6: Bert: But there is not given any speed on the wheels?

7: Simon: (...) because she is on a separate wheel, and then there is a big wheel where that arm is [makes circular gestures in the air to illustrate], and when that has processed one whole round, the smaller one has gone four rounds.
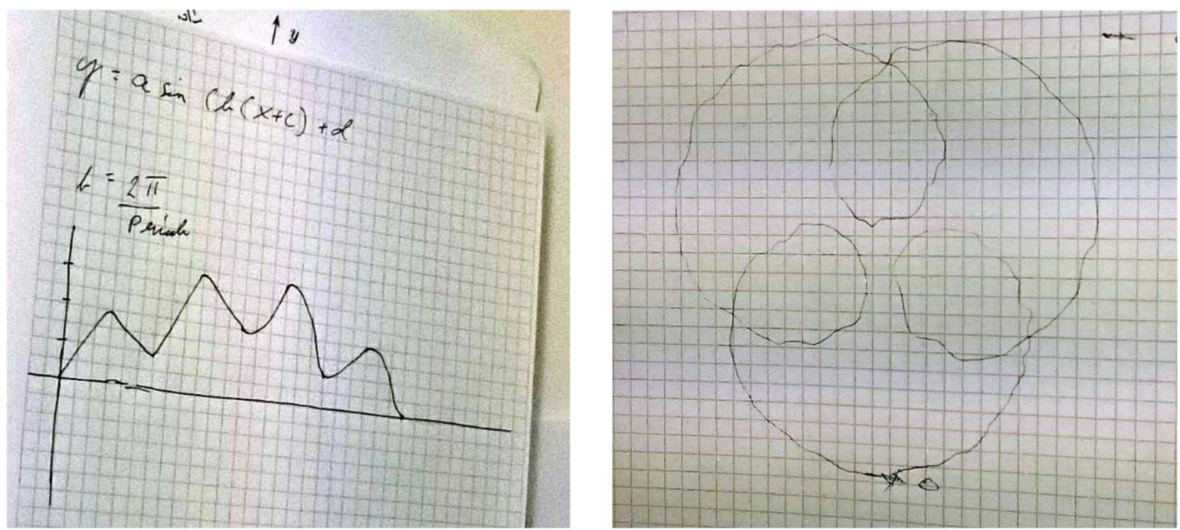

Fig. 5 Highlights of students work at the situational stage of the double Ferris wheel modelling 
Simon is attempting to convey to the others the basic property of the combination of the two movements, using gestures and informal talk about proportions between the periods. We observe that Bert states a need for the quantity 'speed' at line 6 , an initial sign of horizontal mathematization. In the videos, there were many references to circular motions that could support students in their situational stage, both from connecting the unit circle to the sine function, in addition to an example on the rotations of gears.

\section{Guidance on Model-Of}

The notion of guided reinvention in RME positions the teacher as an important participant in the students' activity in developing the transitions between stages in the activity. In both the cases studied here, it seemed that although most student groups did show an ability to create an initial informal representation of the model, the leap to a formal mathematical description seemed to represent a need for guidance. In the case of the skewed $\mathrm{N}$ task, most groups struggled to set up the initial transformation equation, in particular finding the dimensions of the transformation matrix. Some even thought that the vectors to be transformed would be part of the transformation matrix. Observing this, I interrupted the group work for a whole-class discussion on the topic:

23: Me: What is the dimension of the matrices? What is the domain here and the co-domain?

24: Freddy: That is the same.

25: Me: Why the same?

26: Mick: Because the N's are two-dimensional.

27: Me: Both the $\mathrm{N}$ you started with is in two dimensions and the one you ended up with is in two dimensions. What will that have to lead to when it comes to the size of the matrix?

28: Eve: That it will be the same?

29: Me: Yes, it has to be $2 \times 2$. So, the unknown matrix you are looking for is four unknown elements organized in a quadratic way. That is a little hint for you to get you going.

During the elaboration on the matrix size, I phrased the questions in terms of domain and co-domain to make a connection to the elaboration about this in the videos. After this interruption, most student groups were able to set up the transformation based on an unknown $2 \times 2$ matrix which was later found through the information given in the task.

\section{Referential Activity}

Referential activity involves students' elaboration of the model-of where students apply their situational knowledge to organize a mathematical formal description of it. In this respect, models are 'defined to be student-generated ways of interpreting and organizing their mathematical activity, where activity refers to both mental activity and activity with graphs, equations, etc.' (Rasmussen \& Blumenfeld, 2007, p. 198). In an FC context, we might consider the referencing activity to include application of the presituational knowledge acquired through the out-of-class phase. 
An example of this type of activity can be found in the activity of the group consisting of Perry, Matt, Bill and Eve in their work on the Ferris wheel task. Perry claimed he had found the correct expression for the movement:

264: Perry: (...) then the amplitude must be $15 / 2$, and then we took $2 \pi / 5$, that is the period.

266: Bert: $2 \pi / 10$ ?

267: Perry: $2 \pi / 10$, that becomes $\pi / 5$ times $x$ plus 7.5 , because then you move the zero point on the $\mathrm{x}$-axis, and then we had to shift it on the y-axis 15 , that is $15 / 2$, so that the minimum point is on the $x$-axis and then the same thing with the big one.

270: Matt: $2 \pi$ over what? $2 \pi$ over time, or?

271: Perry: $2 \pi$ over the period, it says there (points to the whiteboard).

272: Matt: Yes, and the period was?

273: Eve: What do we call d? (points to the whiteboard).

279: Matt: The equilibrium line (while looking in the notes).

Before the task had been given to the students, I had spent approximately $10 \mathrm{~min}$ repeating the main points on modelling periodic phenomena from the videos. It can be observed that the referencing activity of the students was supported by what I wrote on the whiteboard, but the notes that Matt were looking at stemmed from the videos.

\section{Guidance on Model-For}

Having students create a mathematical model-for a real-life situation is not the main purpose of RME. The idea is that the work with such modelling should lay the foundation for a further exploration towards the general applicability of the theory. This is the idea of the transition from model-of to model-for in RME. Making this leap towards exploring the more general ideas behind the model they have been working on usually requires some form of assistance. The theme 'guidance on model-for' emerged from the data on several occasions, where students started to question generic aspects of the model. One example can be found when Bert, in group 2 during the work with the skewed $\mathrm{N}$ task, started to question the more general ideas behind the layout of a matrix multiplication and the orientation of the input vectors.

249: Bert: Is it a rule that it [it meaning input vectors] must always be oriented downwards, or should it sometimes be oriented the other way?

251: Me: When you are dealing with transformations, the convention is to write it like this.

256: Bert: So it varies from task to task which orientation to choose?

257: Me: Not when you deal with transformations, but matrices can be used in a wide variety of circumstances, so yes, absolutely, you may see it the other way around too.

In line 251, we notice that I guide the student on the conventions of setting up a linear transformation. Organizing knowledge into conventions and labelling/naming different 
objects is also part of the model-for facilitation, but it differs from mathematical knowledge. In particular, the guidance by the teacher to relate such conventions to the discoveries and reflections emerging from students' own activities should lead to stronger conceptual ties.

\section{General Activity and Vertical Mathematization}

General activity involves models-for that facilitate a focus on interpretations and solutions independent of situation specific imagery (Rasmussen \& Blumenfeld, 2007). Such activity does not necessarily involve vertical mathematization, which concerns moving within the abstract world of symbols (Van den Heuvel-Panhuizen \& Drijvers, 2014). However, since reasoning would be of a more formal character during general activity, this type of mathematization is most commonly found here and in the formal activity stage of RME.

During the final phases of group 2's work with the modelling of the Ferris wheel movement, Perry tries to explain his model to the other group members:

255: Perry: We had to analyse the small circle, so we found that the function, height versus time, that becomes $f(x)$, knew the properties by using that formula (points to the whiteboard), so we did the same thing with the big one so that both became correct, then we made another function $h(x)$ which consists of $f(x)$ plus $g(x)$, and then it became the right one.

Perry is here formulating his solutions explaining how he decomposed the mathematical expression into different expressions, each responsible for a separate part of the movement. I would consider this to be vertical mathematization, in the sense that he is moving within the abstract world of symbols through this statement, although referring to formulas on the whiteboard. Notice that this statement is collected from the same period when the group was working on adapting the model during the referential activity mentioned in an earlier section. Not only that, but it also occurs before the referential activity. This shows that the progress between different levels is not necessarily linear.

\section{Discussion}

In this section, I discuss two major findings from the thematic analysis, based on the six themes identified in the previous section. The first relates to how the initial model-for activity in the group work was found to reference pre-situational activity, and the second concerns the importance of teachers' guidance in students' collaborative efforts in transitioning between modelling phases in RME. Then, the dual role of being both a teacher and a researcher is briefly discussed at the end of the section.

\section{Model-for Activity Referencing Pre-Situational Activity}

The flipped RME classroom design introduced in this paper incorporates out-ofclass priming of students through a pre-situational stage, where students watch 
videos and take notes. The idea is to equip students with analytical tools which can form the basis for students' horizontal mathematization during model-for stages. Since I only have indirect access to students' activities in this phase through examining statistics on video-watching, the influence of the presituational activity can only be deduced by analysing what students say during classroom observation. The excerpt from the theme pre-situational referencing showed how Alvin made a direct link to the videos during the groups' situational activity. Similarly, the whole-class interaction with the students during the excerpt from the 'guidance on model-of' theme connected mathematical definitions found in the videos to students' struggling in moving from situational to referential activity. Such labelling and naming of mathematical terms can be considered a vital task for the FC teacher when assisting students in their initial meaningmaking, connecting the analytical pre-situational knowledge to situational activity within the context of the realistic task. These observations align well with the first tenet of RME theory mentioned by Cobb et al. (2008), if one extends the experimentally real situation to include analytical expressions from students' pre-situational engagement with the videos.

The reference to the videos became more indirect when students started to create their own model-of constructs. In the 'Results' section, in the theme Referential activity, Freddy seems to be utilizing the unit circle actively as a mediating tool to find the necessary phase shift for the sine function. The idea of relating properties of the sine function towards the unit circle was also the main ideas in the first video for this session. Matt utilized notes taken from the videos to be able to label individual quantities of the model to names provided in the video, which supported Perry in his efforts to explain his model-of to the group.

Lastly, the activity found in the themes guidance on model-for and 'general activity and vertical mathematization' shows no traces of reference to the pre-situational stage. This is not unexpected, since RME consider model-for activities to be students' efforts of reifying the model-of towards further abstraction and applications in other settings (Gravemeijer, 1999). In an RME context, the analytical tools from the pre-situational activity that formed a basis for the situational and referential activity should become less important when students are positioned for vertical mathematization in their general activity. The diminishing support from the videos in this phase is consistent with the second tenet, in that the vertical mathematization refers to mathematization of one's own mathematical activity, independent of the situational support.

\section{Teachers' Role in the Guiding Reinvention}

Teacher guidance, which emerged as a central finding in the thematic analysis, is consistent in the third tenet of Cobb et al. (2008), which highlights the need to support students' transitions between model-for and model-of activity stages. Even though RME tasks should have a low entry threshold for students through a contextualized, experimentally real foundation, there can be substantial difficulty for students going from situational to referential activity and then further to general and formal activity. Especially so if the mathematics presented in the video-watching, pre-situational stage is unfamiliar. The themes guidance on model-of and guidance on model-for captures this, especially during students' 
work with the skewed $\mathrm{N}$ task, where matrix multiplication and linear transformations were new mathematical content for the students.

Put in a FC perspective, the videos out-of-class could be considered as an initial phase in the guided reinvention, forming a basis for students' engagement with the task in their situational and referential activity. The anticipated innovative processes that students engage in when they work with tasks in class should heighten students' ownership to the 'discovered' mathematics. As such, it is important that the direct type of instruction found in the videos should take a more indirect supporting character in class. 'The idea is to allow learners to come to regard the knowledge they acquire as their own private knowledge, knowledge for which they themselves are responsible' (Doorman \& Gravemeijer, 2009, pp. 200-201). However, in the thematic analysis (see subsections Guidance on model-of and Guidance on model-for in 'Results'), it could be observed that guidance is a necessary ingredient in the reinvention process. During the development of collaborative participation in the modelling process, the teacher should play a proactive role in students' creation, justification and clarification of mathematical concepts (Yackel, 2002).

\section{Reflections About the Validity of the Research}

As I am both the researcher and the teacher in this study, careful consideration needs to be taken in the analysis of the data. A deep discussion on reflexivity and validity (Symon \& Cassell, 2012) of having this dual role is beyond the scope of this article, but various considerations were made during analysis and design. Firstly, this ethnographic study utilizes an interpretative research paradigm (Moschkovich \& Brenner, 2000), allowing me as a researcher to become part of the data collection as a full participant. Moreover, my analysis is based on transcripts of what actually took place in the classroom, not on field-notes and memos. Thus, the data can be considered to be 'raw material', not digested in a certain way by interpretations or filtering. Secondly, the study utilized tasks created in other research settings, somewhat strengthening the external validity of the results. In these other studies, the teachers' role was discussed in depth.

Although I have been conducting all the thematic analysis of the transcripts, several research teams have been overviewing and supervising the process. As such, internal validity of the results should be considered safeguarded.

\section{Concluding Remarks}

In this article, I offer a contribution to research on FC in tertiary mathematics, focusing on the role of task design as an important structuring element in students' activity. Considering RME as a theoretical framework was found to not only affect the in-class activity but extended naturally to the out-of-class phase. We have also seen how teacher guidance forms a vital role in the way students' transition between the various stages in their modelling activity. This may be contrary to the belief of many that the teacher becomes less important when introducing videos as a lecturing component.

Ideally, student engagement with RME tasks should have a longer time span than is allowed for in the setup of a single FC session consisting of one out-of-class and one inclass component. Rather, one would opt for a sequence of tasks in which students first develop a model-of their mathematical activity, which later becomes a model-for more 
sophisticated mathematical reasoning. Although, we can see that when students start developing the model-for a wider application of the mathematics, it is not clearly defined. Time constraints due to the fact that many topics need to be covered in introductory mathematics courses usually makes modelling tasks impractical due to the added time needed (Stillman, 2017). As such, FC video preparations can actually be seen as a way to make RME feasible for tertiary courses, due to a reduced need for lecturing. However, further research might consider instructional designs that span several in-class/out-of-class sessions to allow students' emergent models to grow from a set of tasks as a way to evolve more robust model-for conceptions.

Funding Information Open access funding provided by University of Agder. MatRIC (Centre for Research, Innovation and Coordination of Mathematics Teaching) for funding this research.

Open Access This article is licensed under a Creative Commons Attribution 4.0 International License, which permits use, sharing, adaptation, distribution and reproduction in any medium or format, as long as you give appropriate credit to the original author(s) and the source, provide a link to the Creative Commons licence, and indicate if changes were made. The images or other third party material in this article are included in the article's Creative Commons licence, unless indicated otherwise in a credit line to the material. If material is not included in the article's Creative Commons licence and your intended use is not permitted by statutory regulation or exceeds the permitted use, you will need to obtain permission directly from the copyright holder. To view a copy of this licence, visit http://creativecommons.org/licenses/by/4.0/.

\section{References}

Abeysekera, L., \& Dawson, P. (2015). Motivation and cognitive load in the flipped classroom: Definition, rationale and a call for research. Higher Education Research and Development, 34(1), 1-14. https://doi. org/10.1080/07294360.2014.934336.

Andrews-Larson, C., Wawro, M., \& Zandieh, M. (2017). A hypothetical learning trajectory for conceptualizing matrices as linear transformations. International Journal of Mathematical Education in Science and Technology, 48(6), 809-829. https://doi.org/10.1080/0020739X.2016.1276225.

Bergmann, J., \& Sams, A. (2012). Flip your classroom, reach every student in every class every day. Washington, DC: International Society for Technology in Education.

Bishop, J. L., \& Verleger, M. A. (2013). The flipped classroom: A survey of the research. Paper presented at the 120th American Society for Engineering Education Annual Conference \& Exposition, Atlanta, GA.

Blair, E., Maharaj, C., \& Primus, S. (2015). Performance and perception in the flipped classroom. Education and Information Technologies, 21(6), 1465-1482. https://doi.org/10.1007/s10639-015-9393-5.

Braun, V., \& Clarke, V. (2006). Using thematic analysis in psychology. Qualitative Research in Psychology, 3(2), 77-101. https://doi.org/10.1191/1478088706qp063oa.

Bryman, A. (2008). Social research methods (3rd ed.). Oxford, England: Oxford University Press.

Cobb, P., Zhao, Q., \& Visnovska, J. (2008). Learning from and adapting the theory of realistic mathematics education. Education et didactique, 2(1), 105-124.

Corbin, J., \& Strauss, A. (2008). Basics of qualitative research: Techniques and procedures for developing grounded theory (3rd ed.). Thousand Oaks, CA: SAGE Publications Inc..

Doorman, L. M., \& Gravemeijer, K. P. E. (2009). Emergent modeling: Discrete graphs to support the understanding of change and velocity. ZDM, 41(1), 199-211. https://doi.org/10.1007/s11858-008-0130-z.

Freudenthal, H. (1973). Mathematics as an educational task. Dordrecht, The Netherlands: Reidel Publishing.

Freudenthal, H. (1983). Didactical phenomenology of mathematical structures. Dordrecht, The Netherlands: Reidel Publishing.

Gravemeijer, K. (1997). Solving word problems: A case of modelling? Learning and Instruction, 7(4), 389397. https://doi.org/10.1016/S0959-4752(97)00011-X.

Gravemeijer, K. (1999). How emergent models may foster the constitution of formal mathematics. Mathematical Thinking and Learning, 1(2), 155-177. https://doi.org/10.1207/s15327833mt10102_4. 
Gravemeijer, K., \& Doorman, M. (1999). Context problems in realistic mathematics education: A calculus course as an example. Educational Studies in Mathematics, 39(1), 111-129. https://doi.org/10.1023 /a:1003749919816.

Hadjerrouit, S. (2012). Investigating technical and pedagogical usability issues of collaborative learning with wikis. Informatics in Education, 11(1), 45-64.

Hamdan, N., McKnight, P., McKnight, K., \& Arfstrom, K. M. (2013). A review of flipped learning. Retrieved Nov. 10, 2019 from https://flippedlearning.org/wp-content/uploads/2016/07/LitReview FlippedLearning.pdf

Hwang, G.-J., Lai, C.-L., \& Wang, S.-Y. (2015). Seamless flipped learning: A mobile technology-enhanced flipped classroom with effective learning strategies. Journal of Computers in Education, 2(4), 449-473. https://doi.org/10.1007/s40692-015-0043-0.

Kieran, C., Doorman, M., \& Ohtani, M. (2015). Frameworks and principles for task design. In A. Watson \& M. Ohtani (Eds.), Task design in mathematics education: An ICMI study 22 (pp. 19-81). Cham, Switzerland: Springer International Publishing.

Kuiper, S. R., Carver, R. H., Posner, M. A., \& Everson, M. G. (2015). Four perspectives on flipping the statistics classroom: Changing pedagogy to enhance student-centered learning. PRIMUS, 25(8), 655-682. https://doi.org/10.1080/10511970.2015.1045573.

Love, B., Hodge, A., Grandgenett, N., \& Swift, A. W. (2014). Student learning and perceptions in a flipped linear algebra course. International Journal of Mathematical Education in Science and Technology, 45(3), 317-324. https://doi.org/10.1080/0020739X.2013.822582.

Lundin, M., Bergviken Rensfeldt, A., Hillman, T., Lantz-Andersson, A., \& Peterson, L. (2018). Higher education dominance and siloed knowledge: A systematic review of flipped classroom research. International Journal of Educational Technology in Higher Education, 15(1), 20-30. https://oi. org/10.1186/s41239-018-0101-6.

Miles, M. B., \& Huberman, A. M. (1994). Qualitative data analysis: An expanded sourcebook (2nd ed.). Thousand Oaks, CA: Sage Publications, Inc.

Moschkovich, J. N., \& Brenner, M. E. (2000). Integrating a naturalitic paradigm into research on mathematics and science cognition and learning. In A. E. Kelly \& R. A. Lesh (Eds.), Handbook of research design in mathematics and science education (pp. 457-486). New Jersey: LEA Publishers.

O'Flaherty, J., \& Phillips, C. (2015). The use of flipped classrooms in higher education: A scoping review. The Internet and Higher Education, 25(Supplement C), 85-95. https://doi.org/10.1016/j.iheduc.2015.02.002.

Rasmussen, C., \& Blumenfeld, H. (2007). Reinventing solutions to systems of linear differential equations: A case of emergent models involving analytic expressions. The Journal of Mathematical Behavior, 26(3), 195-210. https://doi.org/10.1016/j.jmathb.2007.09.004.

Rasmussen, C., \& Marrongelle, K. (2006). Pedagogical content tools: Integrating student reasoning and mathematics in instruction. Journal for Research in Mathematics Education, 37(5), 388-420. https://doi.org/10.2307/30034860.

Rasmussen, C., \& Wawro, M. (2017). Post-calculus research in undergraduate mathematics education. In J. Cai (Ed.), Compendium for research in mathematics education (pp. 551-581). Reston, VA: National Council of Teachers of Mathematics.

Sfard, A. (1991). On the dual nature of mathematical conceptions: Reflections on processes and objects as different sides of the same coin. Educational Studies in Mathematics, 22(1), 1-36. https://doi.org/10.1007 /bf00302715.

Stillman, G. A. (2017). Enabling anticipation through visualisation in mathematising real-world problems in a flipped classroom. In G. A. Stillman, W. Blum, \& G. Kaiser (Eds.), Mathematical modelling and applications: Crossing and researching boundaries in mathematics education (pp. 163-173). Cham, Switzerland: Springer International Publishing.

Strayer, J. F. (2012). How learning in an inverted classroom influences cooperation, innovation and task orientation. Learning Environments Research, 15(2), 171-193. https://doi.org/10.1007/s10984-012-9108-4.

Sweeney, G., \& Rasmussen, C. (2014). Reconceiving modeling. An embodied cognition view of modeling. In L. D. Edwards, D. Moore-Russo, \& F. Ferrara (Eds.), Emerging perspectives on gesture and embodiment in mathematics (pp. 197-226). Charlotte, NC: Information Age Publishing.

Symon, G., \& Cassell, C. (2012). Qualitative organizational research: Core methods and current challenges. Thousand Oaks, CA: Sage Publications, Inc.

Van Den Heuvel-Panhuizen, M. (2003). The didactical use of models in realistic mathematics education: An example from a longitudinal trajectory on percentage. Educational Studies in Mathematics, 54(1), 9-35. https://doi.org/10.1023/B:EDUC.0000005212.03219.dc. 
Van den Heuvel-Panhuizen, M., \& Drijvers, P. (2014). Realistic mathematics education. In S. Lerman (Ed.), Encyclopedia of mathematics education (pp. 521-525). Dordrecht, The Netherlands: Springer Netherlands.

Yackel, E. (2002). What we can learn from analyzing the teacher's role in collective argumentation. The Journal of Mathematical Behavior, 21(4), 423-440. https://doi.org/10.1016/S0732-3123(02)00143-8. 